\title{
Derechos humanos y democracia: algunas tensiones teóricas y progmáticas
}

\section{RESUMEN}

Humberto Mejía Zarazúa*

Se abordan algunos aspectos de la relación entre derechos humanos y democracia. Dicha relación es importante para establecer algunas "tensiones" tanto teóricas como prácticas en relación con su universalidad, con su concreción jurídica, con la actuación de organismos multinacionales, con la democracia en América Latina, el culturalismo y el universalismo alrededor de los derechos humanos y la población vulnerable respecto de estos derechos. Se menciona brevemente el caso de México y se finaliza mencionando la relación entre sociedad civil y el futuro de los derechos humanos.

\section{ABSTRACT}

The relationship between human rights and democracy is important in that it sheds light on some theoretical as well as practical "tensions" related to its universality, its legal application, the actions of multinational organizations, democracy in Latin America, the multiculturalism and universalism associated with human rights and the position of vulnerable populations with respect to these rights. The case of Mexico is mentioned briefly and the essay concludes with an overview of the relationship between civil society and human rights.

* Ingeniero Agrícola y Maestro en Ciencias de la Educación. Colaborador de la Dirección de Posgrado e Investigación de la Universidad La Salle Pachuca.humberto_mz@hotmail.com Una definición de derechos humanos

Tanto el concepto de derechos humanos como el de democracia, se invocan por posiciones contrarias en aspectos tanto teóricos como pragmáticos (liberales y republicanos; globalifóbicos y globalifílicos; culturalistas y universalistas). Definir qué son los derechos humanos no es sencillo, a menudo las definiciones no dan cuenta de la complejidad teórica y práctica de los conceptos o nociones; sin embargo, con base en algunas que compilan Maria Elena Ortiz y Greta Papadimitriu (2000) se propone la siguiente: son un conjunto de exigencias éticas y sistemas de valores inacabados y en continua evolución debido a cambiantes condiciones socioculturales, que tienen su expresión en normas jurídicas nacionales e internacionales, que imponen deberes al Estado y conceden facultades a las personas, y que tienen como fin el reconocimiento de la dignidad humana como valor superior a otros ${ }^{1}$. Así, se puede plantear que los derechos humanos tienen tres dimensiones: la histórica, la ética y la legal. Es decir, no pueden aislarse de contextos históricos que influencian la construcción de un sistema de valores con tendencia a la aceptación universal y se plasman en documentos de índole jurídico tanto internacionales (Declaración de 
Derechos Humanos de las Naciones Unidas) como nacionales (garantías individuales y sociales de la Constitución Política de los Estados Unidos Mexicanos, por ejemplo). En esta aportación se plantean algunos rasgos de la relación entre los derechos humanos y la democracia, entendida ésta como "una forma social de participación en la producción, control y distribución del poder político" (Roitman, 2005: 186).

\section{Derechos humanos y democracia: una relación conflictiva}

Tras las terribles experiencias de la primera y segunda guerras mundiales, surgió cierta conciencia pacifista en las naciones directamente afectadas y se reformularon parámetros políticos y culturales respecto de las relaciones internacionales, de manera que en 1948 se aprobó la Declaración de Derechos Humanos de las Naciones Unidas y en las décadas posteriores se negociaron acuerdos acerca de derechos políticos, civiles, económicos, sociales y culturales. Sin embargo, esto no impidió el resurgimiento de guerras locales, ni el ansia colonialista de las naciones desarrolladas y la aún débil, y en ciertos casos hipócrita, condena a las guerras de agresión y a los crímenes contra la humanidad. Como es claro, este cambio no ha sido suficiente para detener la voracidad del capitalismo global que privilegia la hegemonía económica de las naciones poderosas sobre el respeto de los derechos humanos de las naciones periféricas (Habermas, 2000; Stiglitz, 2002).

El desarrollo democrático que incluye una amplia participación ciudadana, no sólo en los procesos electorales, sino en los de rendición de cuentas, democratización institucional y de prácticas cotidianas de los ciudadanos, entre otros, es fuente de respeto a los derechos individuales de las personas y garantía de cohesión social en las actuales sociedades que, debido a la creciente complejidad que alcanzan, son cada vez más diferenciadas. Así, la participación política representa la base de solidaridad, tanto abstracta como jurídica, para la consecución, por un lado, de las soberanías populares (garantía de la autonomía pública de los ciudadanos), como del respeto a los principios de los derechos humanos (dominio legítimo de las leyes). Para Habermas (2000: 103-104):

Los derechos fundamentales, tanto los que garantizan libertades individuales como los de participación política, fundamentan el estatuto ciudadano, estatuto que entretanto se ha vuelto autorreferencial, en la medida que habilita a los ciudadanos unidos democráticamente a conformar su propio estatus mediante la autolegislación. A largo plazo, sólo un proceso democrático que procure un adecuado y justo reparto de derechos puede ser considerado como legítimo y producir solidaridad. Para permanecer como una fuente de solidaridad social, el estatuto de ciudadano debe conservar un valor de uso que se traduce en un efectivo ejercicio de los derechos sociales, ecológicos y culturales.

El respeto y defensa de los derechos humanos en el ámbito mundial, es preocupación de organizaciones ciudadanas internacionales como Human Rights Watch o Amnistía Internacional (Al); sin embargo, otras instituciones mundiales como la misma Organización de las Naciones Unidas (ONU) a menudo no funcionan para tal efecto, puesto que, entre otras razones, no 
permiten la participación democrática de los ciudadanos, ya que es una organización de Estados nacionales, no de los pueblos. Éstos no pueden intervenir en la elección de sus representantes ni vigilar su funcionamiento o participar en el diseño de sus políticas. Asimismo, otros organismos internacionales (Banco Mundial, FMI, OMC, etcétera) toman decisiones que afectan a países e individuos sin la debida participación de éstos, además de que no aceptan la realización de debates públicos, la rendición de cuentas ni la fiscalización de los ciudadanos (Ramírez, 2005).

El debate sobre los derechos humanos tradicionalmente se ha centrado en los derechos civiles y políticos, que si bien son de fundamental importancia, también lo son las demás dimensiones, ya que debido al proceso histórico mundial se han establecido varias generaciones de ellos ${ }^{2}$, lo cual supone una evolución racional, ética y jurídica, sin embargo, ninguno de estos desarrollos implica su aplicación homogénea ya que "la cultura y la práctica de los derechos humanos coexisten con otros sistemas normativos que legitiman la explotación, el abuso, la violencia y la intolerancia" (Lagarde, 2000: 21), puesto que a pesar de ser universales, no abarcan a todas las personas; su naturaleza cultural y política es débil ante megaorganizaciones que detentan el poder y porque las instituciones que los defienden a menudo son menos poderosas que aquellas que los eliminan. Además, la total aplicación de los derechos humanos supone una plena vigencia de vida democrática, tanto en su aspecto formal como sustantivo y en sus dimensiones política, económica y social, ya que "...la democracia para los modernos expresa un procedimiento normativo que debe garantizar el ejercicio de las libertades individuales." (Roitman, 2005: 73).

Republicanos, liberales, universalistas y culturalistas: un debate vigente

Los derechos humanos se basan en un universalismo moral apoyado por una solidaridad cosmopolita, aunque alrededor del concepto de dichos derechos existe aún la tensión entre adeptos del republicanismo y el liberalismo:

Para los primeros, los Derechos Humanos deben su legitimidad a la autocomprensión ética y la autodeterminación soberana de una comunidad política; para los segundos, los Derechos Humanos por sí mismos establecen los límites que deben impedir a la soberana voluntad del pueblo la intrusión en la inviolable esfera de las libertades privadas de los sujetos (Habermas, 2000: 152)

Históricamente se ha buscado un nexo entre los derechos humanos y la soberanía popular (recordemos que en nombre de la soberanía popular se han cometido flagrantes violaciones a los derechos humanos), sin embargo, la autonomía privada y la pública se presuponen mutuamente, ya que la ciudadanía está en posibilidad de hacer valer su autonomía pública gracias a la autonomía privada de cada ciudadano, es decir, los derechos de libertad y los derechos políticos son indivisibles e igualmente esenciales (Habermas, 2000).

Como se mencionó, los derechos humanos tienen la dimensión moral y la jurídica, es decir, a pesar de su contenido moral tienen la forma de derechos 
jurídicos, éstos se concretan en un cuerpo legislativo válido para los ciudadanos de determinado Estado nacional, de ahí que exista una tensión entre su sentido universal y las peculiaridades de su concreción, esta situación idealmente derivaría en el derecho a elegir nacionalidad, cuestión que si bien se ha planteado en el concepto de ciudadanía mundial, se ve aún prácticamente inalcanzable. Sin embargo, la noción de derechos humanos es uno de los fundamentos más claros para plantear una legalidad política de la comunidad internacional, ya que la mayoría de los estados nacionales han aceptado la Declaración de Derechos Humanos de las Naciones Unidas, aunque su validez universal sigue siendo discutida, puesto que hasta ciertos intelectuales radicales de occidente sostienen que dicha validez oculta una perversa pretensión de poder. Aunque para Habermas (2000: 155) “...Saber tomar distancia frente a las propias tradiciones y ampliar las estrechas perspectivas es uno de los logros del racionalismo occidental. La historia europea de la interpretación de los derechos humanos es la historia del descentramiento en nuestra forma de mirar" ${ }^{3}$.

A medida que la sociedad se vuelve más compleja, se crean nuevas identidades culturales más allá de diferencias étnicas, de género o clase social, de modo que es imperativo el reconocer que vivimos en un mundo multicultural que además enfrenta un proceso de globalización caracterizado por su naturaleza uniformizante, lo cual ha intensificado el debate entre los que reivindican el culturalismo y los que se adhieren a la legitimación de las pretensiones universalistas respecto a la concepción teórica de los derechos humanos. Miguel Giusti (s/f) sostiene que es necesario abandonar las posiciones simplistas o fundamentalistas de ambas partes, y que es preciso reconocer las razones que asisten a los críticos de ambas posiciones. El mencionado autor aduce que, en esencia, lo que se critica es la concepción individualista e instrumental subyacente a la noción de los derechos humanos, propia de la cultura occidental, así como sus pretensiones de validez universal.

La posición culturalista en sí no cuestiona la dimensión moral de la defensa de la vida ni la solidaridad humana, sino la noción atomística de la persona y la destrucción de lazos culturales, así como el individualismo presupuesto en los derechos humanos, por el cual se pretende legitimar indirectamente la lógica de mercado, la desintegración de las comunidades culturalistas y la utilización tecnológica de la naturaleza. Además los derechos humanos no son más que un recurso de legitimación y encubrimiento ideológico de las frecuentes violaciones a estos derechos, de manera que el concepto de libertad individual legitima a la ley del mercado, la libertad de expresión a la propiedad privada de los medios de comunicación, el derecho al trabajo a la acumulación de capital, y la libertad de conciencia a la ruptura de la solidaridad social (Giusti, s/f).

Otro argumento de los culturalistas se refiere a la contradicción en la que incurre la sociedad democrática moderna, cuando sostiene que la legitimidad de las decisiones políticas reposa sobre el derecho de la participación de todos los involucrados, pero prescinde de la opinión de las grandes mayorías de los países de la periferia respecto de las decisiones políticas, económicas 
y jurídicas que regulan en buena medida la vida internacional, ya que es obvio que las decisiones tomadas en los centros financieros o en las grandes potencias tienen repercusiones decisivas para la economía, la sociedad y la política de los países en desarrollo (Stigitz, 2002). Así el sistema político internacional incumple sus supuestos principios de fomento a la democracia y respeto a los derechos humanos. De esta manera, los culturalistas cuestionan la hipocresía del mundo occidental rico, que encubren la injusticia de facto del orden económico y político internacional, por medio de un discurso moral que legitima su posición de dominio (Giusti s/f). En este sentido:

Ningún gobierno actual es acusado, por los intelectuales institucionales, antes luchadores por la libertad, de violar los derechos humanos cuando firma políticas de ajuste económico que generan desempleo, hambre y muerte por desnutrición. Tampoco son acusados cuando la población es sometida a un continuo miedo psicológico con discursos tremendistas que señalan el final de la sociedad de pleno empleo, de la seguridad social para todos, etcétera (Roitman, 2005: 87)

Por otro lado, la posición universalista defensora de los derechos humanos sostiene que la posición culturalista expresa una cosmovisión que absolutiza los parámetros de racionalidad o de moral inherente a una cultura específica, y aducen que fue precisamente para dar solución a la disputa entre cosmovisiones culturales que surgió la idea de la tolerancia y respeto a los derechos individuales. Teóricamente la validez universal de los derechos humanos se basa en el iusnaturalismo que implica un esencialismo que otorga validez natural a los derechos de las personas por el sólo hecho de ser humanos; también tienen fundamento en el racionalismo metafísico moral que parte de la filosofía kantiana que postula una normatividad metafísica para garantizar el carácter vinculante del principio de igualdad de los seres humanos; por su parte, las teorías consensuales atribuyen a los participantes en determinado discurso los derechos o la voluntad para concertar principios y acciones por medio del diálogo argumentativo (Giusti, s/f). En este sentido, Marcos Roitman (2005: 83) acota que:

...existe un consenso en declarar la pertinencia de regular aquellos derechos políticos fundamentales e inalienables que deben, por lo tanto, quedar al margen de las peculiaridades cultural-nacionales. Son los llamados derechos del hombre en tanto derechos humanos sociales e individuales asignados a la condición humana independientemente del orden político al cual se esté adscrito.

Los universalistas insisten en que los culturalistas requieren de una concepción moral y jurídica que trascienda los límites de su propia tradición, es decir, que ofrezcan una alternativa de convivencia con las otras posiciones que por principio excluyen. Es decir, hay que evitar el carácter represivo y etnocéntrico de las tradiciones, ya que en defensa de la autonomía y la identidad de la propia tradición, el culturalista olvida que esa misma tradición puede ser fuente de represión de personas o grupos que forman parte de ella. Asimismo los defensores de los derechos humanos como valores universales han denunciado la utilización política del 
culturalismo por parte de gobiernos autoritarios; éstos apelan al derecho de autodeterminación y rechazan las denuncias como formas de intervencionismo (Giusti s/f)).

Para Miguel Giusti (s/f) es necesario abandonar el fundamentalismo reconociendo la validez relativa de las posiciones en disputa. Así el mencionado autor propone una solución dialéctica, entendida ésta como método de resolución de conflictos. Los interlocutores en este debate deberían poder admitir que hay buenas razones que asisten a ambas partes. Un consenso dialéctico sería aquel que resultase del reconocimiento de un conjunto de reglas comunes, para el cual no fuese necesario renunciar a los principios de la propia cosmovisión cultural. En cierto sentido, las diferentes declaraciones de los derechos humanos, en la medida en que han sido reconocidas y firmadas por Estados nacionales, constituyen una forma de consenso dialéctico como el mencionado, pero aún es una forma incipiente para su pleno respeto, porque su vigencia está siendo puesta constantemente en cuestión por nuevos y viejos fundamentalismos.

Con base en lo anterior se plantean las siguientes preguntas: ¿Reconocerán los países ricos que su discurso sobre los derechos humanos encubre una grave desigualdad estructural de orden económico internacional? ¿Admitirán que el estado de las relaciones internacionales habla en contra del discurso igualitario que presupone su defensa universalista de los derechos de la persona? ¿Reconocerán la autonomía de las culturas a las que han mantenido en situación de dominación para posibilitar la aceptación de los derechos humanos como una concepción universal?

¿Reconocerán los defensores del culturalismo el peligro de encapsulamiento de la propia tradición cultural? ¿Abandonarán la instrumentalización del discurso culturalista para fines políticos internos? ¿Serán capaces de ofrecer una alternativa transculturalista que haga posible la convivencia entre diferentes culturas particulares?

Así, en opinión de Rafael Grasa (2000), son seis las cuestiones irresueltas respecto a los derechos humanos:

1. La universalidad de los derechos humanos para todas las sociedades

2. La diferenciada relación individuo-sociedad (según la sociedad de que se trate)

3. Eventual incompatibilidad entre cosmovisiones ético-religiosas (islam, hindú, etc.)

4. Intervención en nombre de los derechos humanos y/o la evitación de intervención humanitaria en nombre de la soberanía nacional

5. El marco de acción y atribuciones de instituciones supranacionales

6. Los recursos financieros para la realización de derechos de segunda y tercera generación

Si bien estos aspectos irresueltos remiten a una dimensión global, en el ámbito cotidiano el ejercicio de los derechos humanos se relaciona con la cada vez más indiferenciada esfera pública y privada ${ }^{4}$, y el interés personal y comunitario ${ }^{5}$, así como la formación de una ciudadanía tolerante y plural. Por otro lado, es innegable la existencia de población vulnerable en sus derechos humanos, representada por los ciudadanos que, 
independientemente de su cantidad, se encuentran en desventaja en relación con la demás población, tales como niños, mujeres, personas con capacidades diferentes, ancianos, indígenas, lesbianas y homosexuales (Ortiz y Papadimitriu, 2000). Es necesario reconocer la exasperante lentitud en que los derechos supuestamente iguales se extienden a los grupos oprimidos, marginados y excluidos (Habermas, 2000). Por el carácter formal que poseen, los derechos humanos son como los principios del liberalismo: tienen vigencia plena sólo en condiciones de igualdad y bajo el supuesto de que las reglas del juego sean compartidas por todos. Por esto algunos teóricos de los derechos humanos han sostenido que es preciso conformar una ciudadanía mundial, en las que todos los seres humanos se ajusten a un mismo sistema de reglas de acción (Giusti s/f).

\section{América Latina y México: deficiente democracia y deficiente respeto a los derechos humanos}

En América Latina es limitado el desarrollo de la democracia debido a la marginalidad social, la exclusión económica, el aumento de la pobreza extrema, la corrupción, la impunidad con que actúan los aparatos represivos del Estado, la concentración de los medios de comunicación en unas cuantas empresas, la destrucción ecológica y la falta de viviendas. Estos problemas afectan a más de 44 por ciento de la población latinoamericana (Dietrich, 1997; Roitman, 2005). Para el contexto latinoamericano, habría que reflexionar acerca de algunas cuestiones que plantea Marcos Roitman (2005: 87):

¿Existe el derecho de expresión en sociedades en las que el $50 \%$ o más de la población está en condiciones de analfabetismo funcional y donde se da un control monopólico y privado de los medios de comunicación social? [...] ¿Es la libertad de asociación un derecho establecido cuando el Estado limita, reprime y no reconoce organizaciones políticas en los procesos de negociación social? ¿Hasta qué punto pueden convivir las tradicionales libertades sociales con sistemas de exclusión y violencia estructurales legitimados en la libertad individual? ¿Es posible que la libertad individual lleve a la libertad social? ¿Son los derechos humanos una variante de la libertad individual o responden a criterios sociales de consideración política y no jurídica?

Para el mencionado autor, estas preguntas se pueden resolver si se parte de concebir la libertad como condición humana y la democracia como régimen político que garantiza su realización, ya que para ejercer la democracia en libertad se requiere de la garantía del bien común.

Respecto a México, existen evidencias de que el gobierno ha ignorado informes que documentan violaciones de derechos humanos ${ }^{6}$, uno de ellos fue elaborado por Human Rights Watch, en su informe mundial en el apartado relativo a México (Nueva York, 11 de enero de 2007) que expresa que "la tortura y el uso excesivo de la fuerza por las autoridades y la impunidad oficial están entre los principales problemas de derechos humanos que padece México" (Gómez, 2007). Otro, elaborado por la Comisión Civil Internacional de Observación de los Derechos Humanos (CCIODH) fue descalificado por la Secretaría de Gobernación, en este 
informe se plantea que:

La comisión considera que los hechos ocurridos en Oaxaca son un eslabón de una estrategia jurídica, policíaca y militar, con componentes sicosociales y comunitarios cuyo objetivo último es lograr el control y amedrentamiento de la población civil en zonas donde se desarrollan procesos de organización ciudadana o movimientos de carácter social no partidista (Gómez, 2007).

Por parte de Al se presentó el informe México, leyes sin justicia: violaciones de derechos humanos e impunidad en el sistema de justicia penal y de seguridad pública, en el cual se sostiene que México es un país de "Leyes sin Justicia" y documenta "violaciones a derechos humanos e impunidad: en casi todo el país se registran detenciones arbitrarias, fabricación de pruebas y tortura" (Ballinas, 2007). Lo anterior se suma al desmantelamiento de la Fiscalía Especializada en Movimientos Sociales y Políticos del Pasado (Ballinas, 2007; Gómez, 2007). En suma, se considera que estos problemas tienen una relación directa con la democracia mexicana, que en palabras de Lorenzo Meyer (2006) es "una democracia mediocre", entre otras cosas por el deficiente Estado de derecho en nuestro país. A propósito de lo anterior, el mencionado autor expresó que:

El Estado de derecho en México es muy difícil, porque desde el momento mismo en que arranca el país como estructura política independiente, la realidad ha ido por un lado y el derecho por otro, y nunca se han encontrado. El derecho se usa más bien -al menos en México, en muchas ocasionespara beneficio de los que pueden manipularlo, de los que saben y pueden manipularlo en detrimento de los que no tienen ni idea. El derecho en México no nació como un derecho propio (Meyer, 2006).

\section{CONCLUSIONES}

Para finalizar, se considera que los derechos humanos han sido ejes alrededor de los cuales se han sostenido, por un lado, una lucha por la dignidad humana en el contexto individual y colectivo y, por otro, un recurso retórico para legitimar procesos de dominación económica y política, así como de exclusión social. Asimismo existe una relación de mutua influencia entre el respeto a los derechos humanos y la democratización de la sociedad, es decir, la democracia genera respeto a los derechos humanos y la lucha por éstos genera democracia (a mayor democracia mayor respeto a los derechos humanos y viceversa). La hipótesis de quien suscribe el presente artículo, es que será la sociedad civil organizada en redes para la comunicación y acción concertada en el nivel local, regional, nacional y mundial, la que definirá el rumbo del ejercicio de los derechos humanos, más que las acciones de los gobiernos de los Estados nacionales y de los organismos internacionales.

${ }^{1}$ Esta definición se basa en las que han establecido Magdalena Aguilar Cuevas, Jesús Antonio de la Torre, José Bonifacio Barba y Mario I. Álvarez, Maria Elena Ortiz y Greta Papadimitriu

${ }^{2}$ La primera generación se refiere a los derechos civiles y políticos (libertad de tránsito, de expresión, derecho a ser electo, derecho al voto, etc.), la segunda generación son los derechos sociales, económicos y culturales (derecho al salario justo, libertad de asociación, a formar parte de la vida 
cultural, etc.), la tercera generación son los derechos de los pueblos (derecho al medio ambiente, a la independencia económica y política, a la paz, etc.), la cuarta generación se refiere a nuevos actores y movimientos sociales (derecho a la opción sexual, al reconocimiento de la diferencia) y la quinta generación surge por las tecnologías de punta: manipulación y calidad genética de la especie humana, clonación de animales y seres humanos, transplantes de órganos, derechos de las especies vivas y de la naturaleza. (Ortiz y Papadimitriu, 2000)

${ }^{3}$ Cursivas de Habermas

4 Un ejemplo es la reciente legislación en México respecto de la violencia intrafamiliar. Es decir, el ámbito privado (familia) también representa un asunto público en lo que a derechos humanos se refiere.

5 Aún es vigente el debate entre los principios liberales y republicanos respecto de las sociedades democráticas.

${ }^{6}$ Enfatizan casos tales como los de San Salvador Atenco, Estado de México; en Oaxaca; en Lázaro Cárdenas, Michoacán; en Guadalajara; los feminicidios de Ciudad Juárez y las desapariciones de personas de la guerra sucia.

\section{FUENTES DE CONSULTA}

- BALLINAS, Victor (2007), Crisis de seguridad y justicia en México: Al, en "La Jornada" (en línea: http://www.jornada.unam.mx) 8 de febrero de 2007 (2007), Rechaza Al compromiso "retórico" de Calderón, en "La Jornada" (en línea: http://www.jornada.unam.mx) 12 de febrero de 2007

- DIETERICH, Heinz (1997), Globalización, educación y democracia en América Latina, en: Chomsky, Noam y Heinz Dieterich, "La sociedad global. Educación, Mercado y Democracia”, México: Joaquín Mortiz

- Giustl, Miguel (s/f), Los derechos humanos en un contexto intercultural. Página web: http://www.campus-oei.org/valores2/giusti2.htm (febrero de 2007)

- Habermas, Jürgen (2000), La constelación posnacional. Ensayos políticos, España: Paidós

- Gómez, Magdalena (2007), Derechos humanos de ocasión, en "La Jornada" (en línea: http://www.jornada.unam.mx), 30 de enero de 2007

- Grasa, Rafael (2000), Seis cuestiones irresueltas a propósito de una definición consensuada, en: Ortiz, Ma Elena y Greta Papadimitriou, "Educación en derechos humanos. Guía metodológica", México: Procuraduría de Protección Ciudadana, Asociación para la Educación en Derechos Humanos, Amnistía Internacional (Sección Mexicana), Universidad Autónoma de Aguascalientes

- Lagarde, Marcela (2000), Educación, género y derechos humanos, en: Ortiz, Ma Elena y Greta Papadimitriou, "Educación en derechos humanos. Guía metodológica”, México: Procuraduría de Protección Ciudadana, Asociación para la Educación en Derechos Humanos, Amnistía Internacional (Sección Mexicana), Universidad Autónoma de Aguascalientes

- Meyer, Lorenzo (2006), Lorenzo Meyer: "una democracia mediocre", Entrevista de Ariel Ruiz Mondragón, en "Metapolítica en linea", Julio-agosto de 2006, http://www.metapolitica.com.mx 
- Ortiz, Ma Elena y Greta Papadimitriou (2000), Educación en derechos humanos. Guía metodológica, México: Procuraduría de Protección Ciudadana, Asociación para la Educación en Derechos Humanos, Amnistía Internacional (Sección Mexicana), Universidad Autónoma de Aguascalientes - Ramírez Sáiz, Juan Manuel (2005), Derechos de los ciudadanos en las decisiones globales, en: Esquivel, Edgar e Israel Covarrubias (Coord), "La sociedad civil en la encrucijada. Los retos de la ciudadanía en un contexto global", México: Cámara de Diputados, ITESM y M. A. Porrúa

- Roitman, Marcos (2005), Las razones de la Democracia en América Latina, México: Siglo XXI.

- Stiglitz, Joseph (2002). El malestar en la globalización, España: Taurus 